Review

\title{
Diverse ubiquitin linkages regulate RIP kinases-mediated inflammatory and cell death signaling
}

\author{
Axel Witt ${ }^{1}$ and Domagoj Vucic ${ }^{* 1}$
}

Members of the RIP kinase family are key regulators of inflammation and cell death signaling implicated in maintaining immune responses and proper tissue homeostasis. Increasing evidence points to post-translational modifications of RIP1, RIP2 and RIP3 as being critical for regulating their function. Ubiquitination and the E3 ligases, such as inhibitors of apoptosis (IAP) proteins and LUBAC, that direct substrate selectivity as well as the deubiquitinating enzymes, such as A20 and OTULIN, that reverse these modifications dictate the outcome of RIP kinase signaling. Perturbation of the tightly regulated RIP1, RIP2 and RIP3 ubiquitination can lead to signaling disbalance in TNF, TLR and NOD1/2-controlled pathways and result in severe human pathologies. In this review, we focus on the biological function of ubiquitin-modifying enzymes in the context of RIP1, RIP2 and RIP3 signaling. We also discuss the impact of deregulated ubiquitin networks in RIP1, RIP2 and RIP3 signaling pathways on human health.

Cell Death and Differentiation (2017) 24, 1160-1171; doi:10.1038/cdd.2017.33; published online 5 May 2017

Facts

- RIP1 ubiquitination is an integral part of TNF-mediated assembly of the TNFR1-associated signaling complex and subsequent NF- $K \mathrm{~B}$ and MAPK activation.

- RIP1 deubiquitination impairs pro-inflammatory gene expression signaling and allows RIP1 translocation to cell death-promoting intracellular complexes.

- RIP1 and RIP3 are ubiquitinated during necroptotic cell death signaling.

- RIP2 ubiquitination is essential for NOD1/2-mediated signaling and production of pro-inflammatory cytokines and chemokines.

\section{Open questions}

- What is the functional role of RIP3 ubiquitination in TLR4 signaling?

- Which E3 ligase(s) mediate necroptotic RIP1/3 ubiquitination?

- What is the physiological role of RIP1 and RIP3 ubiquitination in necroptosis?

- What is the role of RIP2 E3 ligases beside XIAP and LUBAC in NOD1/2 signaling?

The immune system represents the first line of defense against invading pathogens or danger signals and is mediated by pathogen-recognition receptors. Engagement of inflammatory pathways mediated by Toll-like (TLR), NOD-like (NLR), RIG-I like and DNA sensors results in the activation of transcription factors including NF- $\kappa \mathrm{B}$ and consequent release of pro-inflammatory cytokines and chemokines.,2 Tumor necrosis factor (TNF) represents one of the major effector molecules of the inflammatory response that can activate the TNF receptor (TNFR) pathway to further promote the expression of inflammatory genes. The release of effector molecules recruits immune cells to the site of infection or damage to clear the insult. Beside an inflammatory response, cell death also represents an important defense mechanism to eliminate affected cells.

During the last decade, receptor-interacting serine/threonine-protein (RIP and RIPK) kinases were highlighted as key players in inflammatory and cell death signaling pathways (Figure 1). The importance of RIP1-3 in TNF, NLR and TLR controlled pathways and post-translational modifications of RIP kinases have been extensively studied. Aside from phosphorylation, ubiquitination of RIP kinases is probably the most important post-translational modification and different ubiquitin patterns on RIPs are known to dictate the fate of cells. This review will focus on the ubiquitination of RIP kinases 1,2 and 3 , enzymes that mediate these modifications, and human diseases that are associated with deregulated ubiquitination of RIP kinases-regulated pathways.

\section{The ubiquitin system}

Ubiquitination is a post-translational protein modification that mediates covalent attachment of a small $8 \mathrm{kDa}$ ubiquitin protein onto substrate proteins. ${ }^{3}$ This process requires the activity of three distinct classes of enzymes-an ATPdependent ubiquitin-activating enzyme (E1), a ubiquitinconjugating enzyme (E2) and a ubiquitin ligase (E3).

The ubiquitin modification process can result in the attachment of single ubiquitin molecules to substrate proteins (monoubiquitination), or in formation of diverse ubiquitin adducts (polyubiquitination). This is accomplished by the

${ }^{1}$ Department of Early Discovery Biochemistry, Genentech, 1 DNA Way, South San Francisco, CA 94080, USA

${ }^{*}$ Corresponding author: D Vucic, Department of Early Discovery Biochemistry, Genentech, 1 DNA Way, South San Francisco, CA 94080, USA. Tel: +650 2258839 ; Fax: +650 225 6127; E-mail: domagoj@gene.com

Received 16.11.16; revised 10.2.17; accepted 15.2.17; Edited by M Gyrd-Hansen; published online 05.5.17 

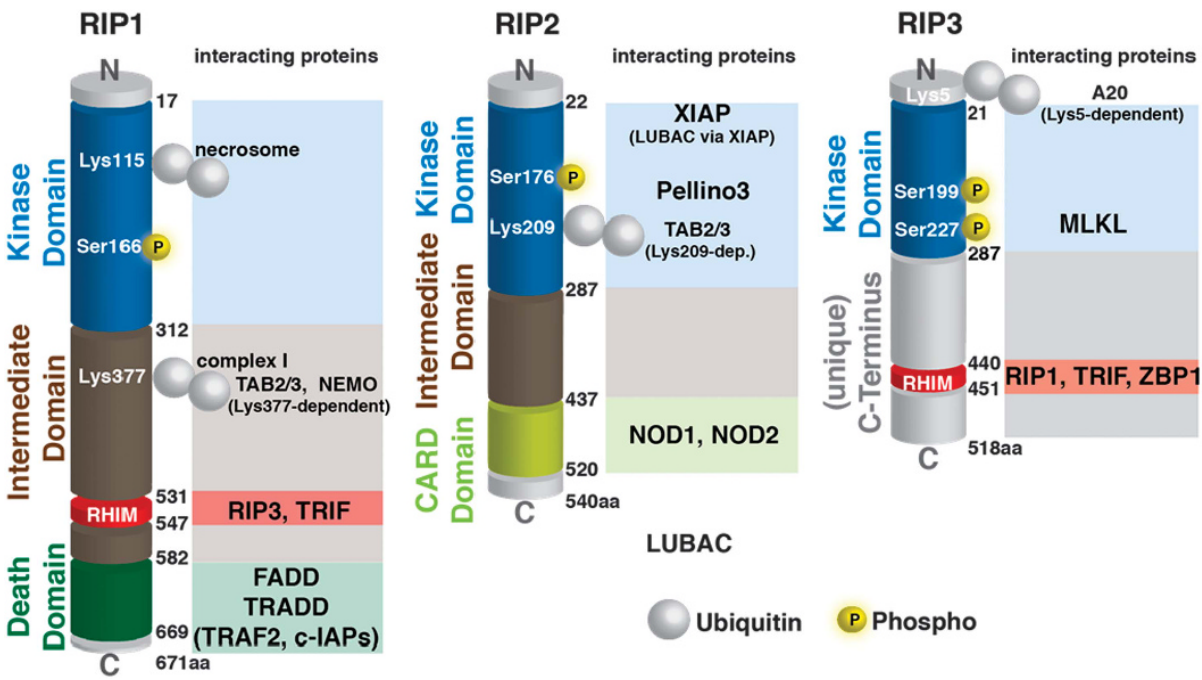

Figure 1 The domain structure of RIP1, RIP2 and RIP3 with RIP-interacting proteins. RIP1, RIP2 and RIP3 consist of amino-terminal kinase domains that harbor phosphosites important for necroptotic signaling (RIP1/S166 and RIP3/S199/277) or NF- $\kappa$ B activation (RIP2/S176). The RHIM domain, located within the intermediate domain of RIP1 and the unique $\mathrm{C}$ terminus of RIP3, is essential for interaction of RHIM-containing proteins and necroptotic signaling. The C-terminal death domain of RIP1 mediates death receptor signaling and apoptosis while the C-terminal CARD domain of RIP2 mediates signaling via NOD1/2 binding. Distinct proteins interact with ubiquitinated RIPs and important ubiquitin sites have been identified for complex I signaling (RIP1/Lys377), NOD signaling (RIP2/Lys209) and necroptosis (RIP1/Lys115 and RIP3/Lys5). In addition, a large number of proteins, like A20, CYLD and LUBAC, use ubiquitin chains as a bridge for interaction with RIPs. Interacting proteins listed in parentheses are indirect binders (TRAF2 and c-IAPs)

conjugation of ubiquitin molecules onto seven internal lysine residues (K6, K11, K27, K29, K33, K48 and K63) of another ubiquitin molecule. Beside internal lysines, the $\mathrm{N}$-terminal methionine (M1) allows formation of M1 or linear ubiquitin linkages. ${ }^{4}$ The diverse modifications of proteins by ubiquitination are linked to complex biological signals required for regulation of distinct physiological processes in cells. ${ }^{5}$ Lys48linked chains predominantly target proteins for proteasomal degradation. ${ }^{3}$ In contrast, Lys63, N-terminal linear and (in some cellular pathways) Lys11-linked chains mainly provide scaffolding for the recruitment and assembly of signaling complexes. $^{6}$ In addition, K63/linear hybrid chains can be formed during inflammatory signaling to regulate the duration of signaling response. ${ }^{7}$

The broad array of specifically targeted substrates explains the great diversity among the E3 ligases (in humans $>500)^{3}$ and several of them are described in the context of RIPdependent pathways (Table 1 and Figure 1). The information contained in various ubiquitin modifications is decoded by distinct ubiquitin-binding domains (UBDs) to ensure transmission of deciphered information into appropriate activation, inhibition or modulation of cellular signaling pathways.

Ubiquitination can be reversed by deubiquitinating enzymes (DUBs) (Table 1). DUBs are involved in generation/recycling of de novo ubiquitin and removal of ubiquitin chains to inhibit protein degradation by the ubiquitin proteasome system, ${ }^{8}$ but also in the regulated cleavage and shielding of polyubiquitin chains to provide a highly dynamic system in cells that modulate protein turnover, activity and localization. ${ }^{9}$ Like E3 ligases, deubiquitinating enzymes can display specificity for substrates and particular ubiquitin chains, resulting in a fine tuned network of ubiquitin-modifying enzymes. This interplay of post-translational modifications represents a key regulatory modality for the RIP kinases that mediate inflammation and cell death signaling.

\section{The regulatory role of RIP1 ubiquitination in complex I}

A tightly regulated ubiquitin network controls various signaling processes that mediate protein stability, inflammation and cell death (Table 1). ${ }^{10}$ One of the key players in these signaling processes is RIP1 and the role of its ubiquitination has been extensively studied in TNFR1 signaling. ${ }^{11-13}$ Receptor trimerization upon TNF binding leads to assembly of TNFR1associated signaling complex, which is referred as complex I (Figure 2). In complex I, the adapter proteins TNFRassociated death domain protein (TRADD) and RIP1 are recruited via their respective death domains. ${ }^{13}$ TRADD in turn recruits adapter proteins TNFR-associated factor-2 (TRAF2). TRAF2 allows the engagement of E3 ligases cellular inhibitors of apoptosis 1 and 2 (C-IAP1 and c-IAP2). ${ }^{14} \mathrm{c}-$ IAP1/2 promote ubiquitination of themselves and RIP1 with $\mathrm{K} 63$, K48 and K11 chains, which is critical for TNFR1 complex I signaling. ${ }^{15-18}$ Polyubiquitin chains conjugated by c-IAP1/2 allow the recruitment of linear ubiquitin assembly complex (LUBAC), which generates exclusively linear ubiquitin chains on several molecules including RIP1, TNFR1, TRADD and NEMO.,12,19-21 LUBAC consists of adapter proteins SHANK-associated $\mathrm{RH}$-domain interactor (SHARPIN) and heme-oxidazid IRP2 ubiquitin ligase 1 (HOIL1) and E3 enzyme HOIL1-interacting protein (HOIP). LUBAC generates M1-linked ubiquitin chains by catalyzing a head-to-tail ubiquitination. Polyubiquitin chains assembled during TNFinduced activation of NF- $k \mathrm{~B}$ and mitogen-activated protein kinases (MAPKs) include but are not limited to K11, K48, K63 and linear chains. ${ }^{15,22,23}$ This ensemble of polyubiquitin 
Table 1 Modification of RIP proteins by E3s and DUBs.

\begin{tabular}{|c|c|c|c|}
\hline Enzyme & Classification & Ubiquitin modification & Associated pathway \\
\hline \multicolumn{4}{|c|}{ Ubiquitin ligase } \\
\hline C-IAP $1 / 2$ & RING E3 ligase & $\begin{array}{l}\text { Transfer of K11-Ub, K48-Ub, K63-Ub on RIP1 } \\
\text { Transfer of K63-Ub on RIP2 }\end{array}$ & $\begin{array}{l}\text { Formation of TNFR-complex I } \\
\text { Inhibition of apoptotic, necroptotic complexes } \\
\text { Formation of NOD } 1 / 2 \text { signaling complex }\end{array}$ \\
\hline XIAP & RING E3 ligase & $\begin{array}{l}\text { Transfer of K63-Ub on RIP2 } \\
\text { (possibly other chains as well) }\end{array}$ & $\begin{array}{l}\text { Formation of NOD } 1 / 2 \text { signaling complex } \\
\text { Negative regulation of apoptosis and } \\
\text { necroptosis }\end{array}$ \\
\hline LUBAC & RBR E3 ligase complex & $\begin{array}{l}\text { Transfer of M1-Ub on RIP1 and RIP2 } \\
\text { Consists of HOIP (catalytic component), HOIL, Sharpin }\end{array}$ & $\begin{array}{l}\text { Enhancement of NF- } \mathrm{KB} \text { and MAPK signaling } \\
\text { Inhibition of complex II formation }\end{array}$ \\
\hline Pellino3 & RING E3 ligase & Transfer of K63-Ub on RIP2 & Supports NOD1/2 signaling \\
\hline \multicolumn{4}{|c|}{ Deubiquitinase } \\
\hline A20 & $\begin{array}{l}\text { OTU-DUB } \\
\text { (UBD: ZNF-A20) }\end{array}$ & $\begin{array}{l}\text { Removal of K63-Ub from RIP1, RIP2 and RIP3 } \\
\text { Binding to M1-Ub, proposed to protect against cleavage } \\
\text { of M1-Ub (RIP1, RIP2) }\end{array}$ & $\begin{array}{l}\text { Decreased complex I signaling favoring } \\
\text { complex II formation } \\
\text { Negative regulator of necroptosis }\end{array}$ \\
\hline CYLD & UCH-DUB & Removal of K63- and M1-linked-Ub from RIP1 and RIP2 & $\begin{array}{l}\text { Decreased complex I signaling } \\
\text { Decreased NLR signaling (NOD1/2) }\end{array}$ \\
\hline OTULIN & OTU-DUB & Selective removal of M1-linked-Ub from RIP1 and RIP2 & $\begin{array}{l}\text { Decreased TNF-induced NF-kB activation } \\
\text { Decreased NOD1/2 signaling }\end{array}$ \\
\hline
\end{tabular}

RIP kinases can be ubiquitinated through the activity of really interesting new gene (RING) E3 ligases ${ }^{114}$ IAPs and Pellinos or by RING-between-RING (RBR) domain E3 complex LUBAC. ${ }^{115}$ Deubiquitinases that disassemble polyubiquitin chains from RIP kinases include ovarian tumor proteases (OTUs) A20 and OTULIN and ubiquitin C-terminal hydrolases (UCHs) CYLD.

UBDs play an important functional and substrate-recognition role for DUBs. The UBDs found in DUBs include the zinc finger ubiquitin-specific protease domain ZNF-A20 (e.g., UBD-domain in A20), the ubiquitin binding in ABINs (UBAN, e.g., UBD-domain in NEMO) and the nuclear protein localization 4 (NPL4) ZnF domain NZF (e.g., UBD-domain in TAB2 and TAB3). ${ }^{114}$

chains serves as a docking platform for the recruitment and retention of the kinase complexes consisting of IKK1, IKK2 and adapter NEMO (IKK $\gamma$; IKK complex), and ubiquitin-binding proteins TAB2/3 and their associated kinase TAK1 (Figure 2). ${ }^{21}$ TAB2/3 specifically bind K63-linked ubiquitin chains, ${ }^{24,25}$ while NEMO can bind to linear, K63- and K11linked polyubiquitin chains ${ }^{15,26}$ with the highest affinity for linear chains. ${ }^{25,27}$ The recruitment of kinase complexes leads to the activation of NF-KB and MAPK signaling and subsequent gene activation and expression of pro-inflammatory cytokines and pro-survival proteins such as the caspase-8 inhibitor cellular FLICE inhibitory protein (cFLIP) or c-IAP2. ${ }^{28}$

Although the current model describes RIP1 polyubiquitination as a crucial step in regulating NF- $\kappa$ B activation in TNFR1 signaling, this is not always the case. It was shown that the absence of RIP1 did not abrogate TNF-induced NF- $k$ B gene expression in MEFs, hepatocytes and some other cell types. $^{29,30}$ It is possible that the role of RIP1 in TNFR1 signaling differs in a cell type-specific manner so that it finetunes the proper pathway activation in a timely fashion. ${ }^{30}$ In this review, we focus on RIP1-dependent signaling in complex I. Deletion analyses and homology comparisons identified K377 of RIP1 as a K63-linked ubiquitin site following TNF stimulation (Figure 1). ${ }^{26,31}$ A K377R mutation in RIP1 diminished the recruitment of complex I components and $N F-\kappa B$ activation ${ }^{26,31}$ and facilitated the switch to cell death complex II formation. ${ }^{32}$ However, K377 is not the only ubiquitination site identified in RIP1 thus far and it was never confirmed by mass spectrometry on endogenous RIP1. Thus, it is possible that additional ubiquitination sites in RIP1 also play a role in NF- $\kappa \mathrm{B}$ and MAPK activation.

The specific polyubiquitination pattern on RIP1 that keeps it in complex I for proper downstream activation of NF- $k B$ and MAPKs is not only fine tuned by the activation of E3 ligases, but also by a negative regulation by DUBs. The importance of the deubiquitinases TNF alpha-induced protein 3 (TNFAIP3 or A20) and cylindromatosis (CYLD) in TNF signaling was demonstrated in vitro and in vivo. A20 is transcriptionally upregulated upon TNF stimulation and was shown to remove K63- and K48-linked ubiquitin (via OTU domain) chains from the RIP1 signaling complex. ${ }^{33,34}$ Genetic A20 ablation in mice and A20 inactivating mutations in humans can lead to increased RIP1 ubiquitination and inflammation (Table 2). ${ }^{35,36}$ But importantly, mice engineered to express catalytically inactive A20 (without DUB activity) or ZF4 mutations do not harbor any inflammatory phenotype contrary to mice lacking $A 20 .^{37,38}$ These data might argue that the scaffolding function of A20 is more critical than its enzymatic activity. Recent findings suggest that $A 20$ promotes cell survival and regulation of NF- $\kappa$ B by binding to linear chains (via ZF7), which prevents their removal by another DUB, CYLD. ${ }^{39,40}$ CYLD can be recruited to complex I by binding to HOIP and recently, spermatogenesis-associated protein 2 was identified as a bridging factor for CYLD and HOIP. ${ }^{41-44}$ CYLD limits NF- $\kappa B$ activation by removing $K 63$ linked and linear polyubiquitin chains on components of complex I. ${ }^{45-47}$ The ubiquitin thioesterase OTULIN (OTU deubiquitinase with linear specifity/FAM105B/Gumby) specifically hydrolyzes Met1-linked polyubiquitin chains. ${ }^{48}$ 


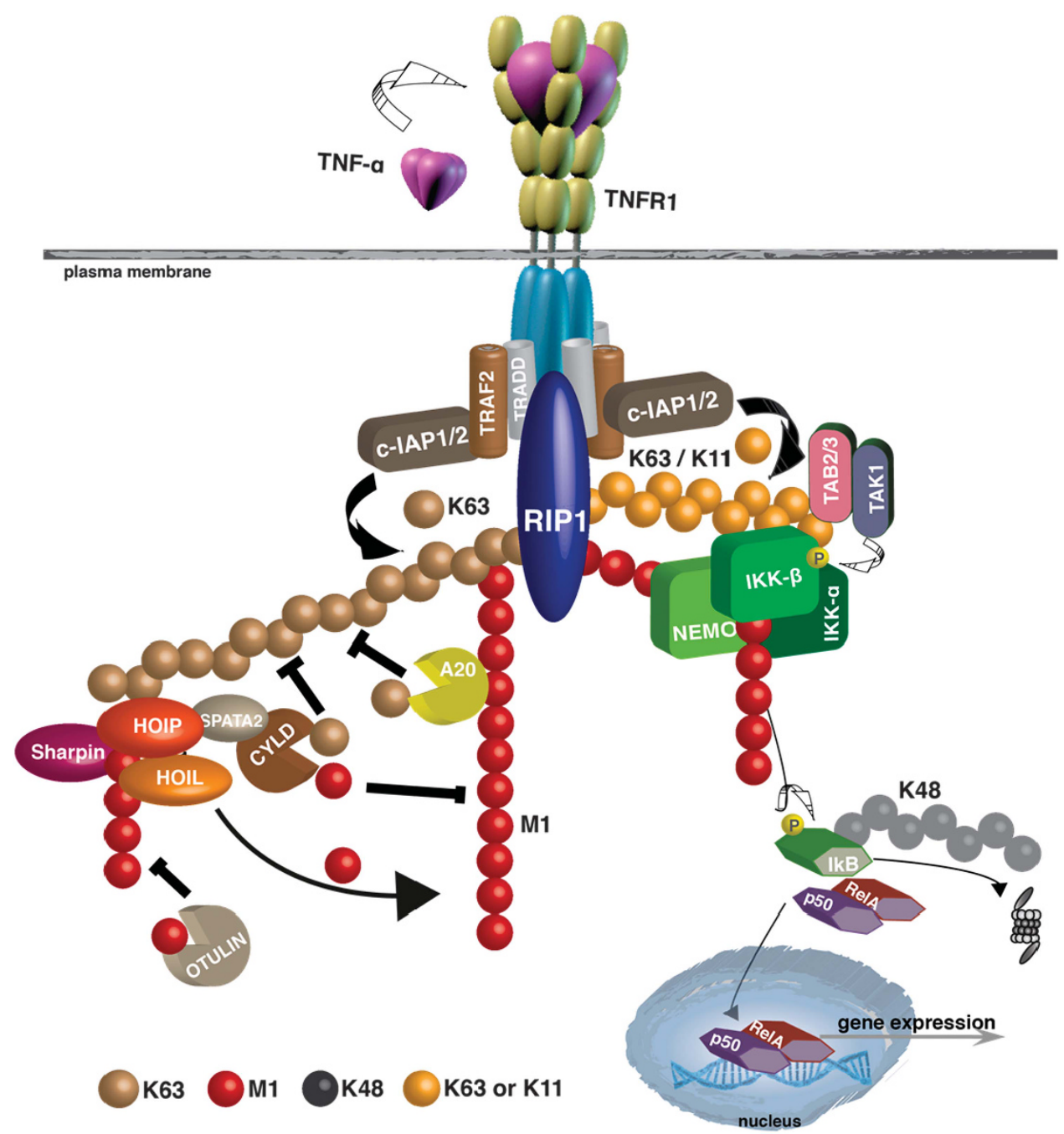

Figure 2 The regulatory role of RIP1 ubiquitination in TNFR1-mediated complex I. TNF stimulation leads to the recruitment of TRADD, TRAF2, C-IAP1/2 and RIP1 to TNFR1. c-IAP proteins polyubiquitinate (K11 and K63) RIP1 and themselves, creating as a scaffold for further recruitment of LUBAC. LUBAC mediates linear polyubiquitin, leading to gene activation via IKK complex. Several DUBs have been implicated in the regulation of RIP1-dependent complex I by removing linear (CYLD and OTULIN) and K63-linked polyubiquitin chains (A20 and CYLD)

OTULIN is not an integral part of the TNFR1-associated signaling complex, but it's DUB activity removes Met1-linked chains on LUBAC. $^{39,49}$ Recently described mutations in OTULIN result in an onset of autoinflammatory disease where patient samples revealed increased levels of linear polyubiquitin. ${ }^{23,50}$ Anti-TNF treatment rescued most disease symptoms but further studies are needed to fully explain what role (if at all) TNF signaling plays in OTULIN-related inflammation (Table 2).

This further illustrates the need for a tightly controlled balance of E3 ligases and DUBs in the assembly and disassembly of K63, K48, K11 and linear polyubiquitin chains on RIP1 and other signaling components. Such fine-tuning is required for the appropriate level of signaling by complex I, and commensurate gene activation. However, RIP1 not only mediates NF- $k \mathrm{~B}$ and MAPK signaling, but also governs a switch toward a pro-cell death fate downstream of TNFR1.

\section{The regulatory role of ubiquitination in RIP1-dependent cell death}

The dynamic changes of post-translational modifications of RIP1 can lead to a switch from inflammatory gene signaling to apoptosis or necroptosis. These changes are regulated by various post-translational modifications of RIP1 and RIP3 and other components of cell death-inducing complexes. In response to inhibited or altered NF- $K B$ signaling, such as genetic deletion of NF- $\kappa B^{51}$ or the presence of transcription or translation inhibitors, a RIP1-independent apoptotic signaling complex can also form. ${ }^{13}$ A cytosolic complex II centered on TRADD recruits Fas-associated death domain (FADD) ${ }^{13,52}$ to activate caspase-8 and cause apoptotic cell death (Figure 3 ).

In the RIP1-dependent formation of apoptotic complex II, distinct ubiquitin modifications play a central regulatory role in dictating the fate of cells (Figure 3 ). In the absence of E3 ligases C-IAP1/2 and LUBAC, unmodified RIP1 dissociates from receptor-associated signaling complex I and associates with 
Table 2 RIP-modifying proteins in human diseases.

\begin{tabular}{ll}
\hline Protein & Associated human diseases \\
\hline A20 & Haploinsufficiency of A20 is the first described germline A20 mutation. ${ }^{36}$ These inactivating A20 mutations results in early onset of \\
systemic inflammation, arthritis and ocular inflammation. Patient-derived cells show reduced enhanced RIP1 ubiquitination and NF- & \\
activation. \\
A20 gene polymorphisms causing lower expression of A20 are associated with rheumatoid arthritis (RA). ${ }^{115}$ Beside RA, A20 \\
mutations have been identified in several autoimmune disorders including Crohn's disease, psoriasis and systemic lupus \\
erythematosus. ${ }^{116}$ \\
A20 acts as a tumor suppressor in distinct cancer types and A20 mutations have been associated with the development of \\
nasopharyngeal carcinoma and head and neck squamous cell carcinoma:;17 diffuse large B-cell lymphona, ${ }^{118-120}$ marginal zone \\
lymphoma, ${ }^{1199,121}$ mucosa-associated lymphoid tissue, ${ }^{120,122}$ Burkitt's lymphoma, ${ }^{122}$ Hodgkin's lymphoma ${ }^{123}$ and mantle cell \\
lymphoma. ${ }^{119}$
\end{tabular}

CYLD Familial cylindromatosis is an autosomal-dominant genetic predisposition to formation of tumors (mostly, skin appendages). ${ }^{124}$ Various mutations are identified in patients with hereditary cylindroma, known as Brooke-Spiegler syndrome ${ }^{125}$ and Paget's disease of the bones. ${ }^{126}$

OTULIN ORAS (OTULIN-related autoinflammatory syndrome): ${ }^{50}$ Homozygous missense mutation (L272P) leads to early onset of autoinflammatory disease. Patient-derived white blood cells show overall elevated M1 chains and anti-TNF treatment reversed inflammatory symptoms in patients.

Otulipenia: ${ }^{23}$ biallelic hypomorphic mutations in three families resulting in severe inflammation. Enhanced M1-linked ubiquitination of NEMO, TNFR and RIP1 in patient-derived cells, which can be countered by cytokine-targeted treatment (like TNF-ab).

XIAP XLP, X-linked lymphoproliferative syndrome 2. Mutations in the BIR2 and RING domains of XIAP impair RIP2 interaction and ubiquitination leading to defective NOD2 signaling and decreased NF-KB activation. ${ }^{98,105,127}$

HOIP Patient with autosomal recessive HOIP deficiency show multi-organ inflammation, combined immunodeficiency, amylopectinosis and systemic lymphangiectasia. Patient-derived fibroblasts harbor defective NF-kB response upon TNF (or IL-1 $\beta$ ). HOIP mutation results in decreased protein level, thus defective LUBAC complex formation. ${ }^{128}$

HOIL Patients with HOIL mutations bear severe chronic autoinflammation, invasive bacterial infections, muscular amylopectinosis. HOIP expression is greatly reduced and LUBAC stability was impaired in response to TLR agonists and TNF in patient-derived cells. ${ }^{129}$

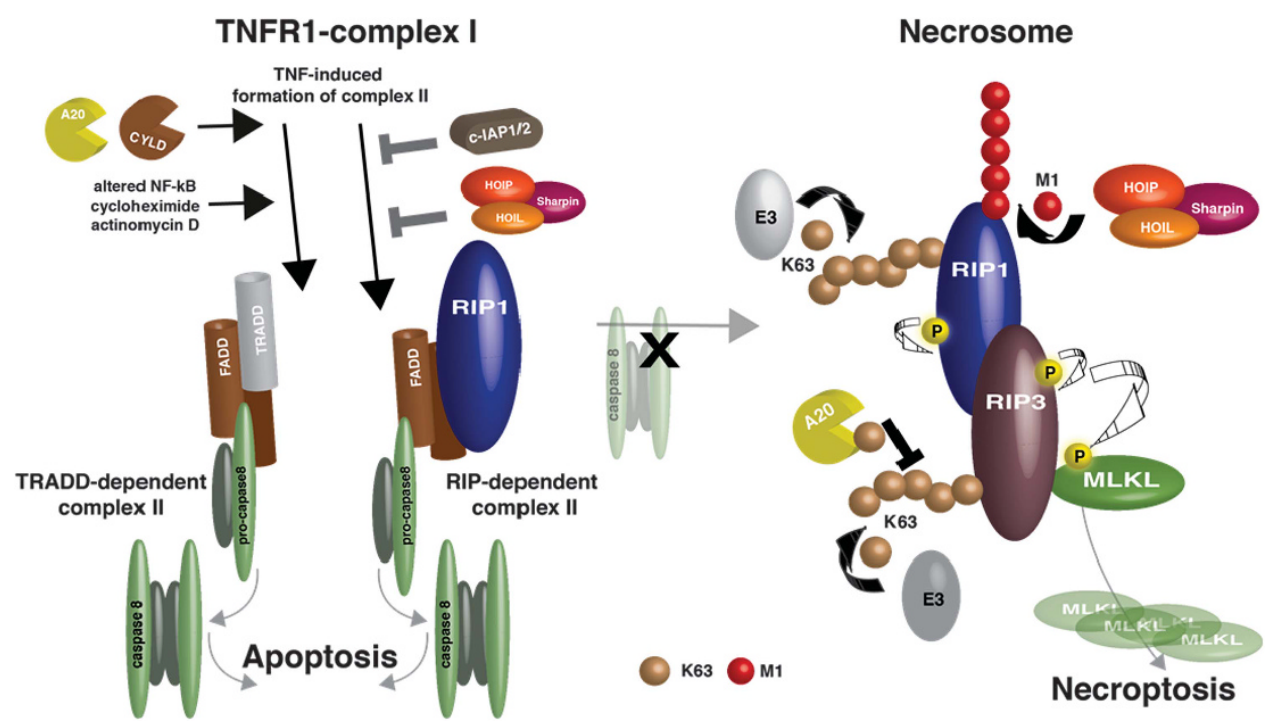

Figure 3 The regulatory role of ubiquitin on RIP1 and RIP3-dependent cell death. Inhibition of transcription or translation can divert TNF-mediated signaling to the formation of an intracellular complex II consisting of TRADD, FADD and caspase-8 in a RIP1-independent apoptotic cell death. This cell death pathway can be promoted by A20 and CYLD that deubiquitinate complex I components and thereby support the switch to complex II. A TNF-induced RIP1-dependent apoptotic cell death occurs in IAP-depleted (by IAP antagonist or KO) or LUBAC-deficient conditions leading to the assembly complex II consisting of RIP1, FADD and caspase-8. Activation of RIP1-dependent cell death under caspase-8 inhibited or deficient conditions can lead to a necroptotic form of cell death that is mediated by RIP1 and RIP3 and results in the activation of MLKL. Recent studies showed various polyubiquitin chains on components of necrosome that are potentially needed for proper formation and function of necrosome

FADD through binding of their DDs. ${ }^{13,17,52}$ FADD recruits procaspase-8 and/or its catalytically inactive homolog FLIP to form the death platform complex II using death effector domain interactions. ${ }^{13}$ Thus, the ubiquitination status of RIP1 can often determine the switch for RIP1 between pro-survival gene activation and cell death. In support of that notion, RIP1 is predominantly not ubiquitinated in caspase-8-associated apoptotic complex. ${ }^{17,52}$ However, some instances, such as combination of TNF treatment and TAK1 inhibition, can lead to retention of ubiquitinated RIP1 in apoptotic complex $11 .{ }^{53}$ In 
addition to TAK1, RIP1 can be kept in check by phosphorylation by IKK complex in NF- $\kappa$ B-independent manner. ${ }^{54}$ Consequently, inhibition of IKKa/IKK $\beta$ or tissue-specific deletion of NEMO can trigger RIP1 kinase activity-dependent apoptosis. ${ }^{54,55}$

In cases when caspase- 8 is absent or inhibited in complex II, RIP3 can bind RIP1 via their RHIM motifs leading to the formation of the necrosome. ${ }^{56,57}$ While the kinase activity of RIP1 is dispensable in complex I, necrosome formation is dependent on RIP1 kinase activity. ${ }^{56,58}$ Within the necrosome, RIP1 and RIP3 engage in auto-phosphorylation that is essential for the execution of necroptotic cell death. Accordingly, chemical inhibition of their kinase function or kinase-inactivating mutations inhibit RIP1/3-dependent necroptotic cell death. ${ }^{56,59,60}$ Phosphorylated RIP3 binds and phosphorylates the pseudokinase mixed lineage kinase domain-like $(\mathrm{MLKL})^{61,62}$ prompting MLKL oligomerization, membrane translocation and cell rupture.

As described before, c-IAP proteins are essential E3 ligases for the assembly of complex I but they also restrict RIP1 translocation to complex II and thereby block cell death (Table 1). ${ }^{56,63-65}$ The physiological link between IAPs and RIP1-dependent cell death is evident from the rescue of the embryonic lethality of $\mathrm{c}-\mathrm{IAP} 1^{-/-} \mathrm{C}-\mathrm{IAP} 2^{-/-}$and $\mathrm{c}-\mathrm{IAP} 1^{-/-}$ $\mathrm{XIAP}^{-1-}$ mice, as hemizygosity for RIP1 was able to prolong the embryonic survival. ${ }^{66}$ The importance of maintaining RIP1 in complex I through its ubiquitination has been illustrated in various mice models. Mice with mutation in Sharpin (cpdm mice) have severe inflammation in skin, liver, lung, oesophagus and lung and exhibit the loss of Peyers patches and splenomegaly. ${ }^{67,68}$ Noteworthy, the phenotype of $c p d m$ mice could be partially rescued by caspase- 8 heterozygosity, which significantly delays dermatitis, whereas RIP3 or MLKL deletion partially suppressed the multi-organ phenotype. ${ }^{68}$ On the other hand, RIP1 kinase inactivation blocked all cpdmrelated pathologies. ${ }^{67}$

Beside E3 ligases that impact the transition of RIP1 toward cell death signaling, deubiquitinating enzymes, such as CYLD, also enhanced cell death in some studies. As described before, CYLD can cleave K63 and linear polyubiquitin chains from components in complex I thereby facilitating a switch to cell death signaling. ${ }^{45-47}$ Interestingly, caspase-8-mediated cleavage of CYLD was shown to inhibit RIP3-dependent cell death and mutation of the caspase-8 cleavage site in CYLD facilitates switch to TNF-stimulated necroptotic cell death. ${ }^{69}$ However, although RIP1 deubiquitination could enhance TNFinduced cell death ${ }^{52,70}$ other data suggest that CYLD is dispensable for necroptotic cell death. ${ }^{39,71} \mathrm{~A} 20$, in comparison, binds linear chains to protect them from cleavage, and thus generates a balance with CYLD to restrict gene activation and/or induce cell death. ${ }^{39}$ A potentially important role in the cell death regulation has been suggested for several other deubiquitinating enzymes of the USP family (USP2a, USP4 and USP21). ${ }^{72-74}$ Although the physiological roles of these DUBs in cell death signaling are less well understood, they may also regulate cell death decisions by modifying the ubiquitination status of their substrate proteins.

\section{RIP1 and RIP3 ubiquitination in the necrosome}

Diverse necroptotic stimuli lead to the activation of cell death through the modulation of RIP1 and/or RIP3 kinase activity. ${ }^{60,75,76}$ However, recent studies imply a more diverse picture of post-transcriptional modifications regulating the necrosome. Initially, it was believed that only RIP1 associated with complex I was decorated with diverse polyubiquitin chains, whereas RIP1 in the necrosome was not ubiquitinated. Recent findings suggest that direct ubiquitination of components within the necrosome occurs as a possible additional regulatory mechanism (Figure 3 ). Different ubiquitin linkages have been identified in the necrosome as RIP1 is modified with linear and K63-linked chains, ${ }^{77-79}$ whereas RIP3 carries K63and K48-linked chains. ${ }^{80,81}$ Generation of M1-linked chains on RIP1 is reported to be mediated by LUBAC in the necrosome but the functional consequence of this modification is unclear at the moment. ${ }^{79}$ Cellular IAP proteins are the E3 ligases in complex I that mediate K63-linked RIP1 ubiquitination and C-IAP1/2 are important negative regulators of necrosome formation. $^{79}$ However, c-IAPs are not relevant for RIP1 polyubiquitination within the necrosome. ${ }^{79}$ Recently, ubiquitination of RIP3 by the E3 ligase CHIP was proposed to confer necrosome instability by targeting RIP3 for lysosomal degradation. ${ }^{81}$ It is important to note that $\mathrm{CHIP}$ regulates the stability of several chaperone heat-shock proteins, which may affect overall cellular protein stability including necrosome components. ${ }^{82}$ Although the functional role of RIP1 ubiquitination within the necrosome is not entirely clear, recent studies have revealed a possible role for specific ubiquitination sites that influence the assembly of RIP1 and RIP3 in the necrosome. ${ }^{78}$ Indeed, mutation of a necroptosis-related ubiquitination site on RIP1 (K115) reduced necroptotic cell death and RIP1 ubiquitination and phosphorylation. It also disrupted necrosome assembly suggesting that necroptotic RIP1 ubiquitination is important for maintaining RIP1 kinase activity in the necrosome complex. ${ }^{78}$ Importantly, RIP1 kinase activity is required for necroptotic RIP1 ubiquitination at K115 and efficient execution of cell death, which involves coordinated RIP1 phosphorylation and ubiquitination. ${ }^{78}$ The question remains whether potential E3 ligases mediate RIP1 ubiquitination in the necrosome or if RIP1 might remain ubiquitinated from the complex I. One can consider another IAP protein, XIAP, as providing support (possibly indirectly) for ubiquitination of RIP1 ${ }^{83}$ XIAP is not associated with complex I, but it suppresses TNF- or LPS-induced cell death and blocks RIP3-dependent ubiquitination on RIP1. Thus, XIAP could influence RIP1 ubiquitination indirectly by either regulating association of RIP1 with its putative E3 ligase or a deubiquitinating enzyme.

A role for DUBs in controlling the necrosome is also complex and currently not fully resolved. The potential of the NF-kB target gene A20 to suppress TNF-induced necroptosis was observed in L929 cells ${ }^{84}$ and in primary mouse T cells. ${ }^{80}$ In this case, A20 can cleave K63-linked ubiquitin chains from RIP3 (on Lys5) leading to reduced RIP1-RIP3 interaction. Interestingly, RIP3 absence or RIP1 kinase inactivation can delay lethality in A20-deficient mice. ${ }^{85}$ However, the importance of A20 DUB activity is not supported by genetic data as the loss of $A 20$ deubiquitinating activity does not result in the same 


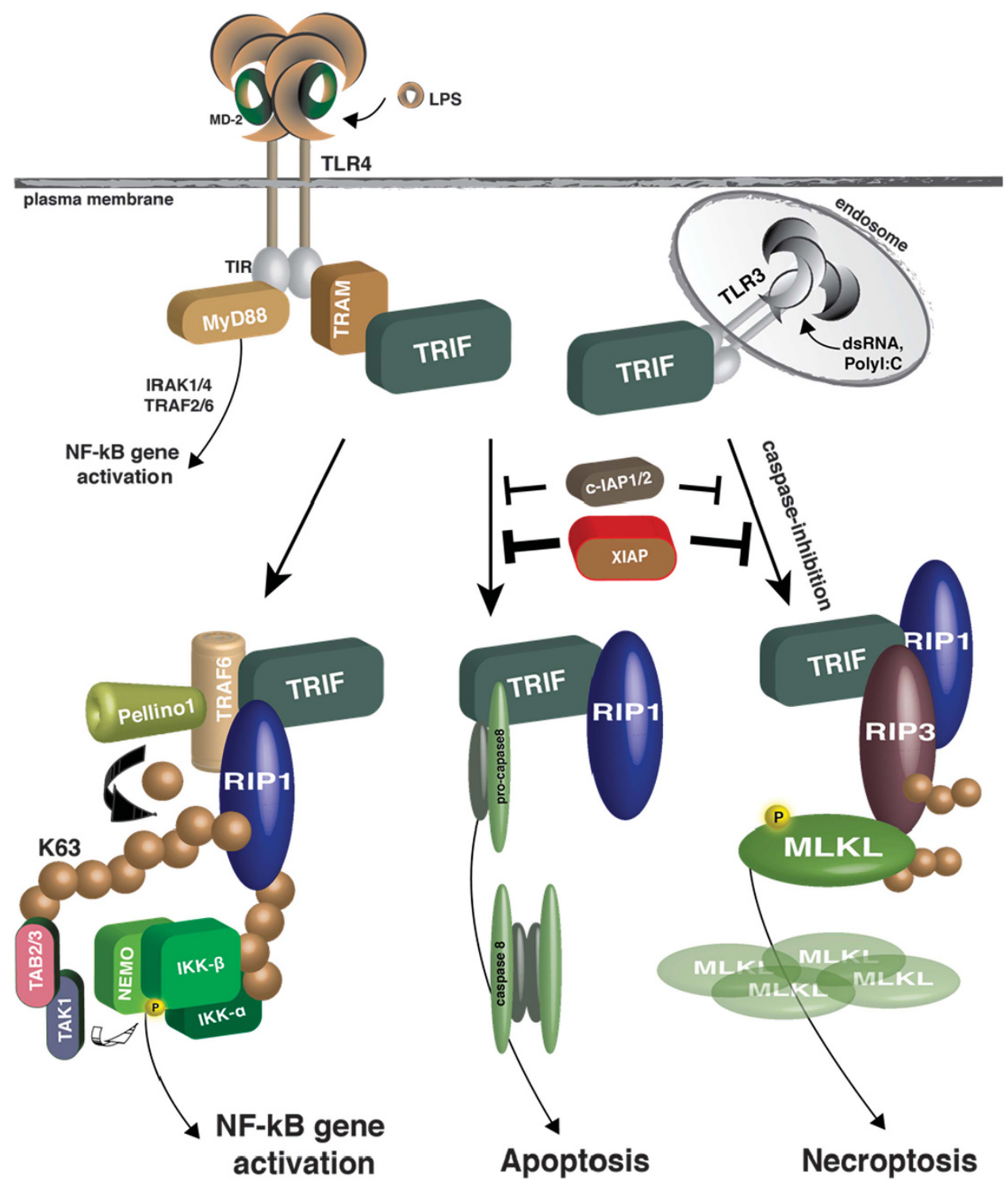

Figure 4 The role of RIP1 and RIP3 polyubiquitination in TLR3 and TLR4 signaling. LPS stimulates TLR4 while dsRNA (or Polyl:C) stimulates TLR3. This activation of TLRs allows TIR (Toll/LL-1 receptor) domain to interact with RHIM-containing TRIF that mediates interaction with RIP1 or RIP3. RIP1-dependent activation of NF- $\kappa B$ is mediated by polyubiquitination by Pellino1, leading to subsequent recruitment and activation of TAB-TAK1 and IKK complexes for NF- $\kappa$ B gene activation. TLR3/4 can induce cell death in a TRIF-RIP1-RIP3-dependent manner, which involves RIP1, RIP3 and MLKL ubiquitination in necroptotic signaling

phenotype as A20 loss. ${ }^{37,38}$ This might point to a DUB activityindependent role of $\mathrm{A} 20$ in necrosome formation. Another DUB CYLD has been reported to deubiquitinate RIP1 in the necrosome leading to enhanced necroptosis. ${ }^{77}$

Even though different necrosome components are modified with various polyubiquitin chains, their biological role is less defined. Polyubiquitinated RIP1 seems to facilitate necrosome formation but the E3 ligases involved in this process have not been identified. K63-polyubiquitinated RIP1 and RIP3 seem to support necrosome formation but the precise function of the different ubiquitin linkages has not been addressed in detail. Identification of RIP1-Lys115 and RIP3-Lys5 as functionally important K63-linked ubiquitin sites supports the idea of a unique ubiquitin profile that fine-tunes necroptotic signaling. Nevertheless, future studies characterizing the network of ubiquitin-modifying enzymes and the identification of specific ubiquitin sites might explain the different roles of RIP1 and RIP3 in necroptotic signaling.

\section{The role of RIP1 and RIP3 polyubiquitination in TLR signaling}

In addition to a key role in DR signaling, RIP1 and RIP3 also regulate PRR pathways, particularly Toll-like receptors (TLRs) family. ${ }^{1}$ TLRs are membrane-associated receptors located at the cell surface (TLR1, 2, 4, 5 and 6) or in endocytic compartments (TLR3, 7, 8 and 9) that recognize signature molecules of pathogens. The role of RIP kinases is best defined in TLR3 and TLR4 signaling (Figure 4). 
TLR3/4 signaling can lead to production of pro-inflammatory cytokines or type-I interferons. TLR3 responds to virus-derived double-strand RNA or its synthetic homolog poly(l:C), whereas lipopolysaccharide (LPS), a major cell wall component of Gram-negative bacteria, is recognized by TLR4 in complex with myeloid differentiation factor- $2 .^{86}$ TLR4 triggers gene activation by engaging the adapter proteins myeloid differentiation primary response protein 88 (MYD88) and TIR domain-containing adapter-inducing interferon $\beta$ (TRIF, which also regulates TLR3 signaling). RIP1 and RIP3 are not required for MYD88 signaling ${ }^{87}$ but RIP1 has been implicated in TRIF-mediated NF- $k$ B activation (Figure 4). ${ }^{88}$ TLR3 directly binds TRIF while TLR4 additionally recruits TRIF-related adapter molecule to bind TRIF. Importantly, TRIF contains a C-terminal RHIM domain that mediates interaction with RIP1 to activate NF- $\kappa$ B signaling. ${ }^{88,89}$ TLR and TRIF form a complex with TRAF6 and the E3 ligase Pellino1, which attaches K63-linked ubiquitin chains on RIP1 leading to subsequent recruitment and activation of TAB-TAK and IKK complexes ultimately resulting in NF- $\kappa \mathrm{B}$ gene activation. ${ }^{90}$

Additionally, TLR3/4 signaling can induce cell death either directly by engaging RIP1 and RIP3, or indirectly by production of TNF and activation of TNFR1 (as discussed earlier in this review). ${ }^{91}$ Direct activation of necroptosis in caspase-inactivated or -deficient conditions can be initiated by interaction of the RHIM domains in TRIF and RIP3 resulting in the activation of MLKL. ${ }^{88,91,92}$ The role of RIP1 is less clear in TLR3/4-mediated necroptotic cell death as the kinase activity of RIP1 is needed for TLR3-mediated cell death in macrophages ${ }^{91,92}$ but not in 3T3-SA fibroblast and SVEC410 endothelial cells. ${ }^{91}$ It is noteworthy that TLR3/4-TRIF signaling might contribute to the lethality of RIP1-deficient mice by engaging RIP3. ${ }^{93}$ LPS-induced cell death signaling is negatively regulated by cellular IAPs and XIAP, such that in the absence of IAPs, LPS triggers RIP3-dependent apoptosis and necroptosis. ${ }^{83,94,95}$ XIAP deficiency may facilitate the switch to TNF- or LPS-induced necroptosis, in a so far unknown mechanism. ${ }^{83,95}$

Interestingly, in addition to the earlier described ubiquitination of RIP1 in necrosome, TLR signaling can also lead to polyubiquitination of RIP3 and MLKL in the necroptotic complex. ${ }^{94}$ The functional role of these modifications remains elusive and the E3 ligases responsible have not been identified yet. Future studies are clearly needed to clarify the biological role of RIP1/3 and MLKL necroptotic polyubiquitination.

\section{The role of polyubiquitination of RIP2 in NOD signaling}

Members of the nucleotide-binding oligomerization domain (NOD)-like receptors (NLRs) family sense conserved peptidoglycan fragments made by various types of bacteria and activate defense mechanisms of the host cell. In contrast to other pathogen-recognition receptors, like TLR4 and TLR3, that detect pattern on the cell surface or endosomal compartments, NLRs, such as NOD1 and NOD2, are located in the cytosol.

NOD1 and NOD2 mediate the activation of NF- $\kappa \mathrm{B}$ and MAPKs in response to distinct peptidoglycan fragments thereby initiating the production of pro-inflammatory cytokines and antimicrobial molecules. ${ }^{2}$ The classic NOD1-activating ligand is $y$-D-glutamyl-meso-diaminopimelic acid (iE-DAP) while NOD2 activation is triggered by muramyl dipeptide. ${ }^{96-98}$ The binding of peptidoglycan fragments to the multiple leucine-rich repeats stimulates self-oligomerization (via NOD/NACHT domain) and allows assembly of the NOD signaling complex. NOD1 and NOD2 recruit RIP2 through the CARD-CARD interactions leading to the formation of a signaling complex that activates the TAB-TAK and IKKNEMO complexes and induce gene activation (Figure 5). ${ }^{99}$

NOD1/2-RIP2 signaling is regulated by distinct ubiquitination events mediated by a number of E3 ligases and DUBs. Lys209, located in the kinase domain of RIP2, was identified as a potential ubiquitination site for K63 polyubiquitin chains. ${ }^{100}$ Polyubiquitination at K209 is reportedly important for IKK activation and proper NF- $K B$ signaling, while the functional relevance of ubiquitination on other lysines in RIP2 is less defined and still needs to be elucidated (Figure 1). Several E3 ligases for RIP2 have been reported. ${ }^{2,101}$ Probably the least controversial and most prominent E3 involved in RIP2-NOD1/2 signaling regulation is XIAP (Figures 1 and 5 and Table 1). XIAP is recruited to the NOD2-RIP2 complex by binding to RIP2 where it mediates RIP2 ubiquitination and promotes recruitment of LUBAC for the formation of linear ubiquitin chains and efficient NF- $k \mathrm{~B}$ and MAPK activation. ${ }^{102,103}$ Further support for the instrumental role of XIAP in NOD-RIP2 signaling comes from the studies of XIAP in human diseases as cells isolated from patients with the $\mathrm{X}$-linked lymphoproliferative syndrome 2 display defects in NOD2-mediated NF- $\kappa$ B activation (Table 2). ${ }^{98,104}$ These studies have identified mutations in the RING and the BIR2 domains of XIAP, with both of them causing defective NOD2 signaling. Strong genetic evidence links NOD2 polymorphisms with the development of Crohn's disease and, interestingly, recently identified XIAP variants lead to a similar selective defect in NOD1/2 signaling. ${ }^{105}$

Cellular IAPs can promote conjugation of K48- and K63linked chains on RIP2, serving as the scaffold for TAB-TAK and IKK complexes. ${ }^{2,102,106}$ However, other studies have shown a redundant role of C-IAP1/2 for NOD2 signaling by using IAP genetic deletions or chemical antagonism. ${ }^{98,102}$ Pellino3 is also a potential E3 ligase in NOD2 signaling that catalyzes K63-linked chains on RIP2 and possibly acts with XIAP in parallel. ${ }^{107}$ The E3 ligase ITCH has been reported to mediate K63-linked polyubiquitination of RIP2 for MAPK signaling as well. ${ }^{108}$ Nevertheless, it was shown that this ubiquitination (on sites other than Lys209) blocks activation of NF- $\kappa$ B suggesting a complex putative role of ITCH in NOD1/2RIP2 signaling. ${ }^{108}$ Although RIP2 polyubiquitination mediated by yet another E3, TRAF6 was implicated in NOD2 pathway, ${ }^{109}$ a subsequent study showed that TRAF6deficient cells still bear polyubiquitinated RIP2. ${ }^{100}$ In addition, ubiquitin ligase TRIM27 was reported to negatively regulate NOD2 signaling by promoting K48-linked ubiquitination of RIP2 and targeting it for proteasomal degradation. ${ }^{110}$ Similar to the negative regulation RIP1-mediated signaling, several DUBs negatively impact NOD1/2-RIP2 signaling by removing polyubiquitin chains from RIP2. A20 directly deubiquitinates RIP2 in vitro and in vivo ${ }^{111}$ while OTULIN inhibits the accumulation of linear chains that are generated by 


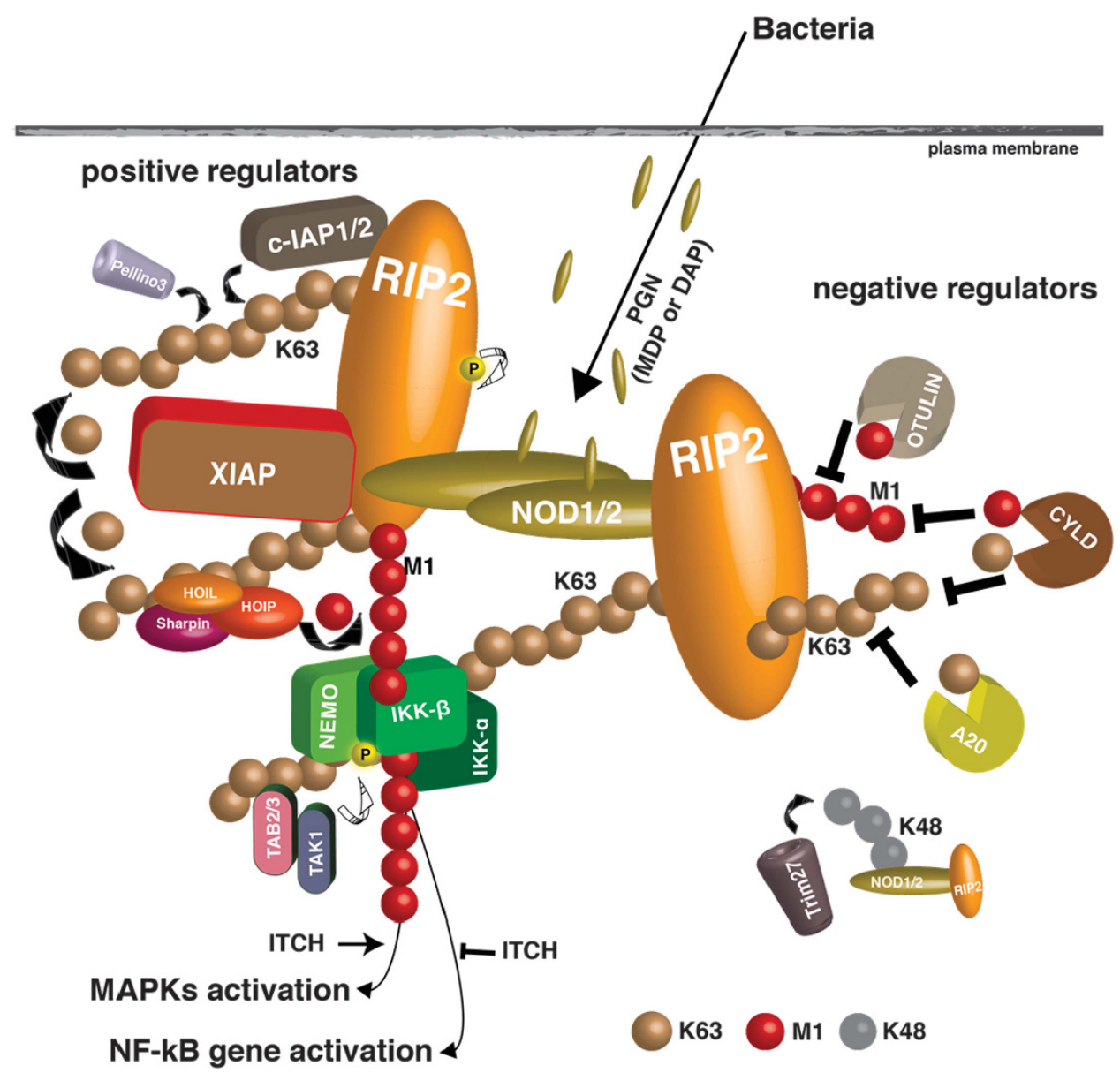

Figure 5 The role of polyubiquitination of RIP2 in NOD1 and NOD2 signaling. Bacterial infection involves secretion of peptidoglycan fragments DAP and muramyl dipeptide to stimulate NOD1- and NOD2-mediated signaling, which leads to RIP2 polyubiquitination and activation of NF- $\kappa$ B or MAPK pathways. A large number of E3 ligases and DUBs are associated with the regulation of RIP2. XIAP promotes K63-linked polyubiquitination on RIP2, leading to generation of LUBAC-mediated linear chains. This allows the activation of the TAB2/3-TAK1 and IKK complexes. Positive regulators, like Pellino3 and c-IAP1/2, also mediate K63-linked chains on RIP2 while removal of polyubiquitin chains by the DUBs OTULIN, CYLD and A20 inhibits NOD1/2-RIP2 signaling

LUBAC. ${ }^{49}$ Additionally, CYLD restricts K63 linked and linear ubiquitin chains conjugated onto RIP2, which limits NOD2-mediated signaling and cytokine production. ${ }^{112}$

The regulation of NOD1/2 and RIP2-mediated activation of $N F-\kappa B$ and MAPKs involves a multitude of ubiquitin-modifying enzymes, which raises many questions. Why are there so many different E3 ligases and DUBs involved? Are their roles dependent on cell context or do they act in a synergistic or collaborative fashion? The role of $\mathrm{c}-\mathrm{IAP} 1 / 2$ remains unclear, and similarly, polyubiquitination of RIP2 at Lys209 may be crucial for NF- $k \mathrm{~B}$ activation but the precise E3 ligase is still not defined and needs to be addressed in further studies.

\section{Concluding remarks}

Tightly controlled activation of signaling pathways, regulation of protein stability and modulation of many other molecular events involving RIP kinases by ubiquitination has profound effects on cell survival and proliferation. Although studies in recent years have yielded many new and important findings, we still lack a full understanding of these processes. Ubiquitin ligases, deubiquitinases and ubiquitin signal decoders all dramatically influence the activity, cellular localization and stability of RIP kinases to ensure generation and propagation of physiological stimuli in a cell type and context-dependent manner. Advancements in gene editing, antibody specificity and assays to detect and interpret cellular signaling outcomes should further improve our knowledge of the roles ubiquitin networks have in the regulation of RIP kinase biology. For example, the emerging targeting degradation strategy of linking E3s to the substrate of choice (PROTACs, proteolysis-targeting chimeras) has been used successfully to trigger selective degradation of RIP2 kinase. ${ }^{113}$

Even more importantly, as we learn about these kinases and their physiological importance, we should strive to develop reagents that can effectively target them for the improvement of human health in conditions where deregulated activity of RIP kinases contributes to pathologies (Table 2). A big part of that effort will be focused on utilizing the ubiquitination machinery to block critical protein-protein interactions, inhibit kinase activity and/or destabilize target proteins. 


\section{Conflict of Interest}

The authors declare no conflict of interest.

Acknowledgements. We thank Kim Newton, Eugene Varfolomeev and Tanya Goncharov for critical reading of the manuscript and helpful comments for the figures. Both authors are employees of Genentech.

1. Kumar $\mathrm{H}$, Kawai $\mathrm{T}$, Akira S. Pathogen recognition by the innate immune system. Int Rev Immunol 2011; 30: 16-34

2. Caruso R, Warner N, Inohara N, Nunez G. NOD1 and NOD2: signaling, host defense, and inflammatory disease. Immunity 2014; 41: 898-908.

3. Hershko A, Ciechanover A. The ubiquitin system. Annu Rev Biochem 1998; 67: 425-479.

4. Tokunaga F, Sakata S, Saeki Y, Satomi Y, Kirisako T, Kamei K et al. Involvement of linea polyubiquitylation of NEMO in NF-kappaB activation. Nat Cell Biol 2009; 11: 123-132.

5. Ikeda F, Dikic I. Atypical ubiquitin chains: new molecular signals. 'Protein Modifications: Beyond the Usual Suspects' review series. EMBO Rep 2008; 9: 536-542.

6. Vucic D, Dixit VM, Wertz IE. Ubiquitylation in apoptosis: a post-translational modification at the edge of life and death. Nat Rev Mol Cell Biol 2011; 12: 439-452.

7. Emmerich $\mathrm{CH}$, Bakshi S, Kelsall IR, Ortiz-Guerrero J, Shpiro N, Cohen P. Lys63/Met1hybrid ubiquitin chains are commonly formed during the activation of innate immune signalling. Biochem Biophys Res Commun 2016; 474: 452-461.

8. Komander D, Clague MJ, Urbe S. Breaking the chains: structure and function of the deubiquitinases. Nat Rev Mol Cell Biol 2009; 10: 550-563.

9. Reyes-Turcu FE, Ventii KH, Wilkinson KD. Regulation and cellular roles of ubiquitin-specific deubiquitinating enzymes. Annu Rev Biochem 2009; 78: 363-397.

10. Corn JE, Vucic D. Ubiquitin in inflammation: the right linkage makes all the difference. Nat Struct Mol Biol 2014; 21: 297-300.

11. Kelliher MA, Grimm S, Ishida Y, Kuo F, Stanger BZ, Leder $P$. The death domain kinase RIP mediates the TNF-induced NF-kappaB signal. Immunity 1998; 8: 297-303.

12. Varfolomeev E, Vucic D. Intracellular regulation of TNF activity in health and disease. Cytokine 2016 (e-pub ahead of print).

13. Micheau O, Tschopp J. Induction of TNF receptor I-mediated apoptosis via two sequential signaling complexes. Cell 2003; 114: 181-190.

14. Rothe M, Pan MG, Henzel WJ, Ayres TM, Goeddel DV. The TNFR2-TRAF signaling complex contains two novel proteins related to baculoviral inhibitor of apoptosis proteins. Cell 1995; 83: 1243-1252.

15. Dynek JN, Goncharov T, Dueber EC, Fedorova AV, Izrael-Tomasevic A, Phu L et al. c-IAP1 and $\mathrm{UbcH} 5$ promote $\mathrm{K} 11$-linked polyubiquitination of RIP1 in TNF signalling. EMBO J 2010; 29: 4198-4209.

16. Varfolomeev E, Goncharov T, Fedorova AV, Dynek JN, Zobel K, Deshayes K et al. c-IAP1 and C-IAP2 are critical mediators of tumor necrosis factor alpha (TNF $\alpha$ )-induced NF-кB activation. J Biol Chem 2008; 283: 24295-24299.

17. Bertrand MJ, Milutinovic S, Dickson KM, Ho WC, Boudreault A, Durkin J et al. clAP1 and cIAP2 facilitate cancer cell survival by functioning as E3 ligases that promote RIP1 ubiquitination. Mol Cell 2008; 30: 689-700.

18. Mahoney DJ, Cheung HH, Mrad RL, Plenchette S, Simard C, Enwere E et al. Both clAP1 and CIAP2 regulate TNFalpha-mediated NF-kappaB activation. Proc Natl Acad Sci USA 2008; 105: 11778-11783.

19. Ikeda F, Deribe YL, Skanland SS, Stieglitz B, Grabbe C, Franz-Wachtel M et al. SHARPIN forms a linear ubiquitin ligase complex regulating NF-kappaB activity and apoptosis. Nature 2011; 471: 637-641.

20. Tokunaga F, Nakagawa T, Nakahara M, Saeki Y, Taniguchi M, Sakata S et al. SHARPIN is a component of the NF-kappaB-activating linear ubiquitin chain assembly complex. Nature 2011; 471: 633-636.

21. Haas TL, Emmerich CH, Gerlach B, Schmukle AC, Cordier SM, Rieser E et al. Recruitment of the linear ubiquitin chain assembly complex stabilizes the TNF-R1 signaling complex and is required for TNF-mediated gene induction. Mol Cell 2009; 36: 831-844.

22. Gerlach B, Cordier SM, Schmukle AC, Emmerich CH, Rieser E, Haas TL et al. Linear ubiquitination prevents inflammation and regulates immune signalling. Nature 2011; 471: 591-596.

23. Zhou Q, Yu X, Demirkaya E, Deuitch N, Stone D, Tsai WL et al. Biallelic hypomorphic mutations in a linear deubiquitinase define otulipenia, an early-onset autoinflammatory disease. Proc Natl Acad Sci USA 2016; 113: 10127-10132.

24. Kanayama A, Seth RB, Sun L, Ea CK, Hong M, Shaito A et al. TAB2 and TAB3 activate the NF-kappaB pathway through binding to polyubiquitin chains. Mol Cell 2004; 15: 535-548.

25. Komander D, Reyes-Turcu F, Licchesi JD, Odenwaelder P, Wilkinson KD, Barford D. Molecular discrimination of structurally equivalent Lys 63-linked and linear polyubiquitin chains. EMBO Rep 2009; 10: 466-473.

26. Ea CK, Deng L, Xia ZP, Pineda G, Chen ZJ. Activation of IKK by TNFalpha requires sitespecific ubiquitination of RIP1 and polyubiquitin binding by NEMO. Mol Cell 2006; 22: 245-257.

27. Rahighi S, Ikeda F, Kawasaki M, Akutsu M, Suzuki N, Kato $R$ et al. Specific recognition of linear ubiquitin chains by NEMO is important for NF-kappaB activation. Cell 2009; 136 : 1098-1109.

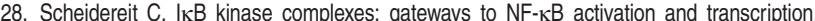
Oncogene 2006; 25: 6685-6705.

29. Wong WW, Gentle IE, Nachbur U, Anderton H, Vaux DL, Silke J. RIPK1 is not essential for TNFR1-induced activation of NF-kappaB. Cell Death Differ 2010; 17: 482-487.

30. Blackwell K, Zhang L, Workman LM, Ting AT, Iwai K, Habelhah H. Two coordinated mechanisms underlie tumor necrosis factor alpha-induced immediate and delayed lkappaB kinase activation. Mol Cell Biol 2013; 33: 1901-1915.

31. Li H, Kobayashi M, Blonska M, You Y, Lin X. Ubiquitination of RIP is required for tumor necrosis factor alpha-induced NF-kappaB activation. J Biol Chem 2006; 281 13636-13643.

32. O'Donnell MA, Legarda-Addison D, Skountzos P, Yeh WC, Ting AT. Ubiquitination of RIP1 regulates an NF-kappaB-independent cell-death switch in TNF signaling. Curr Biol 2007 17: $418-424$.

33. Komander D, Barford D. Structure of the A20 OTU domain and mechanistic insights into deubiquitination. Biochem J 2008; 409: 77-85.

34. Wertz IE, O'Rourke KM, Zhou H, Eby M, Aravind L, Seshagiri S et al. De-ubiquitination and ubiquitin ligase domains of A20 downregulate NF-KB signalling. Nature 2004; 430 694-699.

35. Lee EG, Boone DL, Chai S, Libby SL, Chien M, Lodolce JP et al. Failure to regulate TNF-induced NF-kappaB and cell death responses in A20-deficient mice. Science 2000; 289: 2350-2354.

36. Zhou Q, Wang H, Schwartz DM, Stoffels M, Park YH, Zhang $Y$ et al. Loss-of-function mutations in TNFAIP3 leading to A20 haploinsufficiency cause an early-onset autoinflammatory disease. Nat Genet 2016; 48: 67-73.

37. Lu TT, Onizawa M, Hammer GE, Turer EE, Yin Q, Damko E et al. Dimerization and ubiquitin mediated recruitment of A20, a complex deubiquitinating enzyme. Immunity 2013; 38 896-905.

38. Wertz IE, Newton K, Seshasayee D, Kusam S, Lam C, Zhang J et al. Phosphorylation and linear ubiquitin direct A20 inhibition of inflammation. Nature 2015; 528: 370-375.

39. Draber P, Kupka S, Reichert M, Draberova H, Lafont E, de Miguel D et al. LUBAC-recruited CYLD and A20 regulate gene activation and cell death by exerting opposing effects on linear ubiquitin in signaling complexes. Cell Rep 2015; 13: 2258-2272.

40. Tokunaga F, Nishimasu H, Ishitani R, Goto E, Noguchi T, Mio K et al. Specific recognition of linear polyubiquitin by A2O zinc finger 7 is involved in NF-kappaB regulation. EMBO J 2012 31: 3856-3870.

41. Elliott PR, Leske D, Hrdinka M, Bagola K, Fiil BK, McLaughlin SH et al. SPATA2 links CYLD to LUBAC, activates CYLD, and controls LUBAC signaling. Mol Cell 2016; 63: 990-1005.

42. Kupka S, De Miguel D, Draber P, Martino L, Surinova S, Rittinger K et al. SPATA2-mediated binding of CYLD to HOIP enables CYLD recruitment to signaling complexes. Cell Rep 2016; 16: 2271-2280.

43. Schlicher L, Wissler M, Preiss F, Brauns-Schubert $P$, Jakob $C$, Dumit V et al. SPATA2 promotes CYLD activity and regulates TNF-induced NF-kappaB signaling and cell death. EMBO Rep 2016; 17: 1485-1497.

44. Wagner SA, Satpathy S, Beli P, Choudhary C. SPATA2 links CYLD to the TNF-alpha receptor signaling complex and modulates the receptor signaling outcomes. EMBO J2016 35: $1868-1884$.

45. Brummelkamp TR, Nijman SM, Dirac AM, Bernards R. Loss of the cylindromatosis tumour suppressor inhibits apoptosis by activating NF-kappaB. Nature 2003; 424: 797-801.

46. Kovalenko A, Chable-Bessia C, Cantarella G, Israel A, Wallach D, Courtois G. The tumour suppressor CYLD negatively regulates NF-kappaB signalling by deubiquitination. Nature 2003; 424: 801-805

47. Trompouki E, Hatzivassiliou E, Tsichritzis T, Farmer H, Ashworth A, Mosialos G. CYLD is a deubiquitinating enzyme that negatively regulates NF-kappaB activation by TNFR family members. Nature 2003; 424: 793-796.

48. Rivkin E, Almeida SM, Ceccarelli DF, Juang YC, MacLean TA, Srikumar T et al. The linear ubiquitin-specific deubiquitinase gumby regulates angiogenesis. Nature 2013; 498: $318-324$

49. Fiil BK, Damgaard RB, Wagner SA, Keusekotten K, Fritsch M, Bekker-Jensen S et al. OTULIN restricts Met1-linked ubiquitination to control innate immune signaling. Mol Cell 2013; 50: 818-830.

50. Damgaard RB, Walker JA, Marco-Casanova P, Morgan NV, Titheradge HL, Elliott PR et al. The deubiquitinase OTULIN is an essential negative regulator of inflammation and autoimmunity. Cell 2016; 166: 1215-30 e20.

51. Van Antwerp DJ, Martin SJ, Kafri T, Green DR, Verma IM. Suppression of TNF-alphainduced apoptosis by NF-kappaB. Science 1996; 274: 787-789.

52. Wang L, Du F, Wang X. TNF-alpha induces two distinct caspase-8 activation pathways. Cell 2008; 133: 693-703.

53. Dondelinger Y, Aguileta MA, Goossens V, Dubuisson C, Grootjans S, Dejardin E et al. RIPK3 contributes to TNFR1-mediated RIPK1 kinase-dependent apoptosis in conditions of cIAP1/2 depletion or TAK1 kinase inhibition. Cell Death Differ 2013; 20 : 1381-1392.

54. Dondelinger $Y$, Jouan-Lanhouet S, Divert T, Theatre E, Bertin J, Gough PJ et al. NF-kappaB-independent role of IKKalpha/IKKbeta in preventing RIPK1 kinase-dependent apoptotic and necroptotic cell death during TNF signaling. Mol Cell 2015; 60: 63-76.

55. Vlantis K, Wullaert A, Polykratis A, Kondylis V, Dannappel M, Schwarzer R et al. NEMO prevents RIP kinase 1-mediated epithelial cell death and chronic intestinal inflammation by NF-kappaB-dependent and -independent functions. Immunity 2016; 44: 553-567. 
56. He S, Wang L, Miao L, Wang T, Du F, Zhao L et al. Receptor interacting protein kinase-3 determines cellular necrotic response to TNF-alpha. Cell 2009; 137: 1100-1111.

57. Sun X, Yin J, Starovasnik MA, Fairbrother WJ, Dixit VM. Identification of a novel homotypic interaction motif required for the phosphorylation of receptor-interacting protein (RIP) by RIP3. J Biol Chem 2002; 277: 9505-9511.

58. Cho YS, Challa S, Moquin D, Genga R, Ray TD, Guildford M et al. Phosphorylation-driven assembly of the RIP1-RIP3 complex regulates programmed necrosis and virus-induced inflammation. Cell 2009; 137: 1112-1123.

59. Degterev A, Hitomi J, Germscheid M, Ch'en IL, Korkina O, Teng X et al. Identification of RIP1 kinase as a specific cellular target of necrostatins. Nat Chem Biol 2008; 4: 313-321.

60. Newton K, Dugger DL, Wickliffe KE, Kapoor N, de Almagro MC, Vucic D et al. Activity of protein kinase RIPK3 determines whether cells die by necroptosis or apoptosis. Science 2014; 343: 1357-1360.

61. Zhao J, Jitkaew S, Cai Z, Choksi S, Li Q, Luo J et al. Mixed lineage kinase domain-like is a key receptor interacting protein 3 downstream component of TNF-induced necrosis. Proc Natl Acad Sci USA 2012; 109: 5322-5327.

62. Sun L, Wang H, Wang Z, He S, Chen S, Liao D et al. Mixed lineage kinase domain-like protein mediates necrosis signaling downstream of RIP3 kinase. Cell 2012; 148: 213-227.

63. Vince JE, Wong WW, Khan N, Feltham R, Chau D, Ahmed AU et al. IAP antagonists target CIAP1 to induce TNFalpha-dependent apoptosis. Cell 2007; 131: 682-693.

64. Zhang DW, Shao J, Lin J, Zhang N, Lu BJ, Lin SC et al. RIP3, an energy metabolism regulator that switches TNF-induced cell death from apoptosis to necrosis. Science 2009 ; 325: 332-336.

65. Varfolomeev E, Blankenship JW, Wayson SM, Fedorova AV, Kayagaki N, Garg P et al. IAP antagonists induce autoubiquitination of c-IAPs, NF-KB activation, and TNF $\alpha$-dependent apoptosis. Cell 2007; 131: 669-681.

66. Moulin M, Anderton H, Voss AK, Thomas T, Wong WW, Bankovacki A et al. IAPs limit activation of RIP kinases by TNF receptor 1 during development. EMBO J 2012; 31 1679-1691.

67. Berger SB, Kasparcova V, Hoffman S, Swift B, Dare L, Schaeffer M et al. Cutting edge: RIP1 kinase activity is dispensable for normal development but is a key regulator of inflammation in SHARPIN-deficient mice. J Immunol 2014; 192: 5476-5480.

68. Rickard JA, Anderton H, Etemadi N, Nachbur U, Darding M, Peltzer N et al. TNFR1dependent cell death drives inflammation in Sharpin-deficient mice. eLife 2014; 3: e03464.

69. O'Donnell MA, Perez-Jimenez E, Oberst A, Ng A, Massoumi R, Xavier R et al. Caspase 8 inhibits programmed necrosis by processing CYLD. Nat Cell Biol 2011; 13: 1437-1442.

70. Wright A, Reiley WW, Chang M, Jin W, Lee AJ, Zhang M et al. Regulation of early wave of germ cell apoptosis and spermatogenesis by deubiquitinating enzyme CYLD. Dev Cell 2007; 13: 705-716.

71. Bonnet MC, Preukschat D, Welz PS, van Loo G, Ermolaeva MA, Bloch W et al. The adaptor protein FADD protects epidermal keratinocytes from necroptosis in vivo and prevents skin inflammation. Immunity 2011; 35: 572-582.

72. Mahul-Mellier AL, Pazarentzos E, Datler C, Iwasawa R, AbuAli G, Lin B et al. De-ubiquitinating protease USP2a targets RIP1 and TRAF2 to mediate cell death by TNF. Cell Death Differ 2012; 19: 891-899.

73. Hou X, Wang L, Zhang L, Pan X, Zhao W. Ubiquitin-specific protease 4 promotes TNF-alpha-induced apoptosis by deubiquitination of RIP1 in head and neck squamous cell carcinoma. FEBS Lett 2013; 587: 311-316.

74. Xu G, Tan X, Wang H, Sun W, Shi Y, Burlingame S et al. Ubiquitin-specific peptidase 21 inhibits tumor necrosis factor alpha-induced nuclear factor kappaB activation via binding to and deubiquitinating receptor-interacting protein 1. J Biol Chem 2010; 285: 969-978.

75. Newton K. RIPK1 and RIPK3: critical regulators of inflammation and cell death. Trends Cell Biol 2015; 25: 347-353.

76. Kaiser WJ, Daley-Bauer LP, Thapa RJ, Mandal P, Berger SB, Huang C et al. RIP1 suppresses innate immune necrotic as well as apoptotic cell death during mammalian parturition. Proc Natl Acad Sci USA 2014; 111: 7753-7758.

77. Moquin DM, McQuade T, Chan FK. CYLD deubiquitinates RIP1 in the TNFalpha-induced necrosome to facilitate kinase activation and programmed necrosis. PIOS ONE 2013; 8 e76841.

78. de Almagro MC, Goncharov T, Izrael-Tomasevic A, Duttler S, Kist M, Varfolomeev E et al Coordinated ubiquitination and phosphorylation of RIP1 regulates necroptotic cell death. Cell Death Differ 2017; 24: 26-37.

79. de Almagro MC, Goncharov T, Newton K, Vucic D. Cellular IAP proteins and LUBAC differentially regulate necrosome-associated RIP1 ubiquitination. Cell Death Dis 2015; 6 : e1800.

80. Onizawa M, Oshima S, Schulze-Topphoff U, Oses-Prieto JA, Lu T, Tavares R et al. The ubiquitin-modifying enzyme A20 restricts ubiquitination of the kinase RIPK3 and protects cells from necroptosis. Nat Immunol 2015; 16: 618-627.

81. Seo J, Lee EW, Sung H, Seong D, Dondelinger Y, Shin J et al. CHIP controls necroptosis through ubiquitylation- and lysosome-dependent degradation of RIPK3. Nat Cell Biol 2016; 18: 291-302.

82. Li D, Xu T, Cao Y, Wang H, Li L, Chen S et al. A cytosolic heat shock protein 90 and cochaperone CDC37 complex is required for RIP3 activation during necroptosis. Proc Nat Acad Sci USA 2015; 112: 5017-5022.

83. Yabal M, Muller N, Adler H, Knies N, Gross CJ, Damgaard RB et al. XIAP restricts TNF- and RIP3-dependent cell death and inflammasome activation. Cell Rep 2014; 7: 1796-1808.
84. Vanlangenakker $\mathrm{N}$, Vanden Berghe $\mathrm{T}$, Bogaert $\mathrm{P}$, Laukens $\mathrm{B}$, Zobel $\mathrm{K}$, Deshayes $\mathrm{K}$ et al. CIAP1 and TAK1 protect cells from TNF-induced necrosis by preventing RIP1/RIP3-dependent reactive oxygen species production. Cell Death Differ 2011; 18: $656-665$

85. Newton K, Dugger DL, Maltzman A, Greve JM, Hedehus M, Martin-McNulty B et al. RIPK3 deficiency or catalytically inactive RIPK1 provides greater benefit than MLKL deficiency in mouse models of inflammation and tissue injury. Cell Death Differ 2016; 23: 1565-1576.

86. Nagai $Y$, Akashi S, Nagafuku M, Ogata M, Iwakura Y, Akira S et al. Essential role of MD-2 in LPS responsiveness and TLR4 distribution. Nat Immunol 2002; 3: 667-672.

87. Takeuchi O, Akira S. Pattern recognition receptors and inflammation. Cell 2010; 140: 805-820.

88. Meylan E, Burns K, Hofmann K, Blancheteau V, Martinon F, Kelliher M et al. RIP1 is an essential mediator of Toll-like receptor 3-induced NF-kappa B activation. Nat Immunol 2004; 5: 503-507.

89. Cusson-Hermance N, Lee TH, Fitzgerald KA, Kelliher MA. Rip1 mediates the Trifdependent toll-like receptor 3 and 4-induced NF-kappa B activation but does not contribute to IRF-3 activation. J Biol Chem 2005; 280: 36560-36566.

90. Chang M, Jin W, Sun SC. Peli1 facilitates TRIF-dependent Toll-like receptor signaling and proinflammatory cytokine production. Nat Immunol 2009; 10: 1089-1095

91. Kaiser WJ, Sridharan H, Huang C, Mandal P, Upton JW, Gough PJ et al. Toll-like receptor 3-mediated necrosis via TRIF, RIP3, and MLKL. J Biol Chem 2013; 288: 31268-31279.

92. He S, Liang $Y$, Shao F, Wang $X$. Toll-like receptors activate programmed necrosis in macrophages through a receptor-interacting kinase-3-mediated pathway. Proc Natl Acad Sci USA 2011; 108: 20054-20059.

93. Dillon CP, Weinlich R, Rodriguez DA, Cripps JG, Quarato G, Gurung P et al. RIPK1 blocks early postnatal lethality mediated by caspase-8 and RIPK3. Cell 2014; 157: 1189-1202.

94. Lawlor KE, Khan N, Mildenhall A, Gerlic M, Croker BA, D'Cruz AA et al. RIPK3 promotes cell death and NLRP3 inflammasome activation in the absence of MLKL. Nat Commun 2015; 6: 6282.

95. Wicki S, Gurzeler U, Wei-Lynn Wong W, Jost PJ, Bachmann D, Kaufmann T. Loss of XIAP facilitates switch to TNFalpha-induced necroptosis in mouse neutrophils. Cell Death Dis 2016; 7: e2422.

96. Masumoto J, Yang K, Varambally S, Hasegawa M, Tomlins SA, Qiu S et al. Nod1 acts as an intracellular receptor to stimulate chemokine production and neutrophil recruitment in vivo. J Exp Med 2006; 203: 203-213.

97. Kobayashi KS, Chamaillard M, Ogura Y, Henegariu O, Inohara N, Nunez G et al. Nod2dependent regulation of innate and adaptive immunity in the intestinal tract. Science 2005; 307: 731-734

98. Damgaard RB, Fiil BK, Speckmann C, Yabal M, zur Stadt U, Bekker-Jensen S et al. Disease-causing mutations in the XIAP BIR2 domain impair NOD2-dependent immune signalling. EMBO Mol Med 2013; 5: 1278-1295.

99. Inohara N, Koseki T, Lin J, del Peso L, Lucas PC, Chen FF et al. An induced proximity model for NF-kappa B activation in the Nod1/RICK and RIP signaling pathways. J Biol Chem 2000; 275: 27823-27831.

100. Hasegawa M, Fujimoto Y, Lucas PC, Nakano H, Fukase K, Nunez G et al. A critical role of RICK/RIP2 polyubiquitination in Nod-induced NF-kappaB activation. EMBO J 2008; 27: 373-383.

101. Zinngrebe J, Montinaro A, Peltzer N, Walczak H. Ubiquitin in the immune system. EMBO Rep 2014; 15: 28-45.

102. Damgaard RB, Nachbur U, Yabal M, Wong WW, Fiil BK, Kastirr M et al. The ubiquitin ligase XIAP recruits LUBAC for NOD2 signaling in inflammation and innate immunity. Mol Cell 2012; 46: 746-758.

103. Krieg A, Correa RG, Garrison JB, Le Negrate G, Welsh K, Huang Z et al. XIAP mediates NOD signaling via interaction with RIP2. Proc Natl Acad Sci USA 2009; 106: 14524-14529.

104. Latour S, Aguilar C. XIAP deficiency syndrome in humans. Semin Cell Dev Biol 2015; 39: 115-123.

105. Zeissig Y, Petersen BS, Milutinovic S, Bosse E, Mayr G, Peuker K et al. XIAP variants in male Crohn's disease. Gut 2015; 64: 66-76.

106. Bertrand MJ, Doiron K, Labbe K, Korneluk RG, Barker PA, Saleh M. Cellular inhibitors of apoptosis CIAP1 and CIAP2 are required for innate immunity signaling by the pattern recognition receptors NOD1 and NOD2. Immunity 2009; 30: 789-801.

107. Yang S, Wang B, Humphries F, Jackson R, Healy ME, Bergin R et al. Pellino3 ubiquitinates RIP2 and mediates Nod2-induced signaling and protective effects in colitis. Nat Immunol 2013; 14: 927-936.

108. Tao M, Scacheri PC, Marinis JM, Harhaj EW, Matesic LE, Abbott DW. ITCH K63ubiquitinates the NOD2 binding protein, RIP2, to influence inflammatory signaling pathways. Curr Biol 2009; 19: 1255-1263.

109. Yang Y, Yin C, Pandey A, Abbott D, Sassetti C, Kelliher MA. NOD2 pathway activation by MDP or Mycobacterium tuberculosis infection involves the stable polyubiquitination of Rip2. J Biol Chem 2007; 282: 36223-36229.

110. Zurek B, Schoultz I, Neerincx A, Napolitano LM, Birkner K, Bennek E et al. TRIM27 negatively regulates NOD2 by ubiquitination and proteasomal degradation. PloS ONE 2012; 7: e41255. 
111. Hitotsumatsu O, Ahmad RC, Tavares R, Wang M, Philpott D, Turer EE et al. The ubiquitinediting enzyme A20 restricts nucleotide-binding oligomerization domain containing 2-triggered signals. Immunity 2008; 28: 381-390.

112. Hrdinka M, Fiil BK, Zucca M, Leske D, Bagola K, Yabal M et al. CYLD limits Lys63- and Met1-linked ubiquitin at receptor complexes to regulate innate immune signaling. Cell Rep 2016; 14: 2846-2858.

113. Bondeson DP, Mares A, Smith IE, Ko E, Campos S, Miah AH et al. Catalytic in vivo protein knockdown by small-molecule PROTACs. Nat Chem Biol 2015; 11: 611-617.

114. Dikic I, Wakatsuki S, Walters KJ. Ubiquitin-binding domains - from structures to functions. Nat Rev Mol Cell Biol 2009; 10: 659-671.

115. Zhu L, Wang L, Wang X, Zhou L, Liao Z, Xu L et al. Characteristics of A20 gene polymorphisms and clinical significance in patients with rheumatoid arthritis. J Transl Med 2015; 13: 215.

116. Hymowitz SG, Wertz IE. A20: from ubiquitin editing to tumour suppression. Nat Rev Cancer 2010; 10: 332-341.

117. Codd JD, Salisbury JR, Packham G, Nicholson LJ. A20 RNA expression is associated with undifferentiated nasopharyngeal carcinoma and poorly differentiated head and neck squamous cell carcinoma. J Pathol 1999; 187: 549-555.

118. Compagno M, Lim WK, Grunn A, Nandula SV, Brahmachary M, Shen $Q$ et al. Mutations of multiple genes cause deregulation of NF-kappaB in diffuse large B-cell lymphoma. Nature 2009; 459: 717-721.

119. Honma K, Tsuzuki S, Nakagawa M, Karnan S, Aizawa Y, Kim WS et al. TNFAIP3 is the target gene of chromosome band 6q23.3-q24.1 loss in ocular adnexal marginal zone B cell lymphoma. Genes Chromosomes Cancer 2008; 47: 1-7.

120. Kato M, Sanada M, Kato I, Sato Y, Takita J, Takeuchi K et al. Frequent inactivation of A20 in B-cell lymphomas. Nature 2009; 459: 712-716.

121. Novak U, Rinaldi A, Kwee I, Nandula SV, Rancoita PM, Compagno M et al. The NF-\{kappa\} $B$ negative regulator TNFAIP3 (A20) is inactivated by somatic mutations and genomic deletions in marginal zone lymphomas. Blood 2009; 113: 4918-4921.
122. Honma K, Tsuzuki S, Nakagawa M, Tagawa H, Nakamura S, Morishima Y et al. TNFAIP3 A20 functions as a novel tumor suppressor gene in several subtypes of non-Hodgkin lymphomas. Blood 2009; 114: 2467-2475.

123. Schmitz R, Hansmann ML, Bohle V, Martin-Subero Jl, Hartmann S, Mechtersheimer G et al. TNFAIP3 (A20) is a tumor suppressor gene in Hodgkin lymphoma and primary mediastinal B cell lymphoma. J Exp Med 2009; 206: 981-989.

124. Bignell GR, Warren W, Seal S, Takahashi M, Rapley E, Barfoot R et al. Identification of the familial cylindromatosis tumour-suppressor gene. Nat Genet 2000; 25 160-165.

125. Hu G, Onder M, Gill M, Aksakal B, Oztas M, Gurer MA et al. A novel missense mutation in CYLD in a family with Brooke-Spiegler syndrome. J Invest Dermatol 2003; 121: 732-734.

126. Sundaram K, Shanmugarajan S, Rao DS, Reddy SV. Mutant p62P392L stimulation of osteoclast differentiation in Paget's disease of bone. Endocrinology 2011; 152 : 4180-4189.

127. Rigaud S, Fondaneche MC, Lambert N, Pasquier B, Mateo V, Soulas $P$ et al. XIAP deficiency in humans causes an X-linked lymphoproliferative syndrome. Nature 2006; 444 110-114.

128. Boisson B, Laplantine E, Dobbs K, Cobat A, Tarantino N, Hazen M et al. Human HOIP and LUBAC deficiency underlies autoinflammation, immunodeficiency, amylopectinosis, and lymphangiectasia. J Exp Med 2015; 212: 939-951.

129. Boisson B, Laplantine E, Prando C, Giliani S, Israelsson E, Xu Z et al. Immunodeficiency, autoinflammation and amylopectinosis in humans with inherited HOIL-1 and LUBAC deficiency. Nat Immunol 2012; 13: 1178-1186.

130. Deshaies RJ, Joazeiro CA. RING domain E3 ubiquitin ligases. Annu Rev Biochem 2009 78: $399-434$.

131. Stieglitz B, Rana RR, Koliopoulos MG, Morris-Davies AC, Schaeffer V, Christodoulou E et al. Structural basis for ligase-specific conjugation of linear ubiquitin chains by HOIP. Nature 2013; 503: 422-426 